\title{
Analysis of the Law of Organic Solid Phase Precipitation and Deposition during Carbon Dioxide Displacement Process
}

\author{
Peng Yu ${ }^{1,2}$ \\ ${ }^{1}$ Guangxi Colleges and Universities Key Laboratory of Beibu Gulf Oil and Natural Gas Resource Effective Utilization, Beibu Gulf \\ University, Qinzhou, China \\ ${ }^{2}$ College of Petroleum and Chemical Engineering, Beibu Gulf Universtiy, Qinzhou, China \\ Email: developoil@163.com
}

How to cite this paper: Yu, P. (2019). Analysis of the Law of Organic Solid Phase Precipitation and Deposition during Carbon Dioxide Displacement Process. Journal of Geoscience and Environment Protection, 7, 118-122.

https://doi.org/10.4236/gep.2019.71010

Received: December 29, 2018

Accepted: January 27, 2019

Published: January 30, 2019

Copyright $\odot 2019$ by author(s) and Scientific Research Publishing Inc. This work is licensed under the Creative Commons Attribution International License (CC BY 4.0).

http://creativecommons.org/licenses/by/4.0/

\begin{abstract}
Carbon Capture, Utilization and Storage (CCUS) has been regarded as an indispensable, strategic and pressing technology to reduce anthropogenic carbon dioxide emissions, and mitigate the severe consequences of climate change. Its utilization and storage play important roles in this system and they can be applied for oceanic and underground geological sequestration especially for the oil gas reservoir that needs to improve recovery. For the carbon dioxide flooding process, the crude oil displacement generally shows a better performance with the increase of the pressure. However, carbon disposal is always complex. It could encounter organic solid phase precipitation and deposition in near miscibility environment. The law of multiphase and multicomponent diversification in the whole processes is still poorly understood. We thus used the method of slim tube to get dynamic data during the process. Indeed, the interval of near minimum miscibility pressure was determined. Analysis results of injectivity index and productivity index show that the reservoir blockage primarily appears as the displacement pressure is higher than the near minimum miscibility lower limit pressure and plays an important role in the production capacity. Extortionate or low pressure is not conducive to carbon dioxide displacement.
\end{abstract}

\section{Keywords}

Organic Solid Phase, Precipitaion and Deposition, Carbon Dioxide Displacement, Blockage, Near Minimum Miscibility Pressure

\section{Introduction}

Enhanced oil recovery techniques involve reservoir injection of gases, such as 
carbon dioxide and light hydrocarbons, among gas injection type medium, carbon dioxide is preferred over hydrocarbon gases because of its high flooding utility, relative lower cost and the potential for accompanying environmental profits through its disposal in the porous media (Gale, 2004; Haszeldine, 2009; Gershenzon, 2015; Dai, 2018). However, carbon dioxide displacement system brings about several changes of multiphase and multicomponent behavior of reservoir, and often causes organic solid phase deposition that blocks porous media throats and thus decreases reservoir permeability (Shelton \& Yarborough, 1977; Stalkup, 1983; Tuttle, 1983; Monger, 1985; Mazzocchi et al., 1998). The organic solid phase precipitation and deposition, mostly paraffin and asphaltic components, can obviously reduce crude oil recovery and operation benefits. According on statistics of work regions, several reservoir blocks have been eliminated from candidacy for gas injection scheme because of serious organic solid phase troubles (Danesh et al., 1988; Björn, 1995; Srivastava et al., 1999; Newberry \& Barker, 2000). Little can be done to restore formation damage which caused by organic solid phase deposition. The aim of this study was to explore the law of organic solid phase precipitation and deposition during carbon dioxide displacement process.

\section{Experiment Part}

Minimum miscibility pressure (MMP) is a critical parameter in carbon dioxide displacement system which is defined as the smallest pressure where fluid medium achieves miscibility dynamically (Zendehboudi et al., 2013; Zhang et al., 2018). Rathmell et al. (1971) found that the minimum miscibility pressure grows with volatile fractions. They also concluded that the existence of intermediates $\left(C_{2}\right.$ to $\mathrm{C}_{6}$ ) reduces the value of minimum miscibility pressure. The slim tube has been used by a lot of scholars in the oil industry as the criterion experiment method for measuring the minimum miscibility pressure. It is usually fine and long in order to permit full occurrence of dynamic miscible process. Flooding in this type of tube approach is nearby the perfect performance. Viscous fingering developing is limited by walls of the tube. It is supposed that fluids are mixed evenly due to small diameter of the tube and tube physical condition is close to homogeneous media.

Follow the experimental test step strictly in slim tube experiment process (Figure 1) and the typical oil samples which were utilized in test were taken from Beibu Gulf offshore oilfield. Finally, the near minimum miscibility pressure interval (that is the displacement pressure when the recovery percent of reserves is in the range of $80 \%-90 \%$ ) was determined about $27.23-30.39 \mathrm{MPa}$.

\section{Dynamic Observation of Organic Solid Phase}

A constant pressure displacement method was used during flooding process. Under the stable pressure, the change of flow parameters corresponding to the variation of capacities of crude oil and carbon dioxide in slim tubes. The injectivity index and productivity index could be calculated by the injection pressure difference, injection and production volume per unit time. 


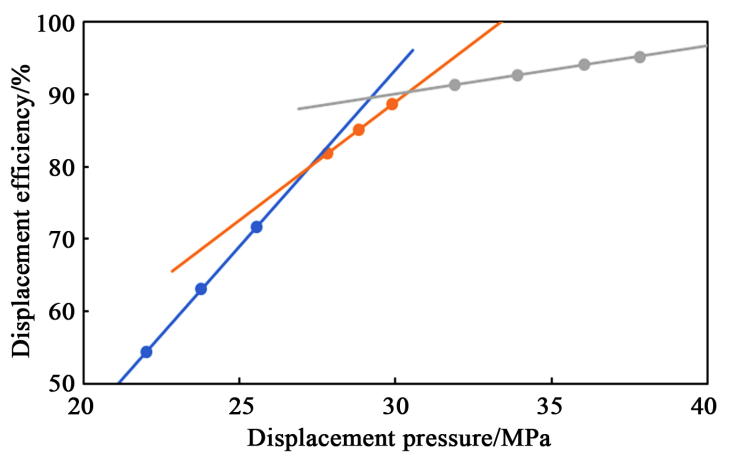

Figure 1. Relationship between displacement efficiency and pressure.

$$
\begin{aligned}
& I_{\text {in }}=Q_{\text {in }} /(t \cdot \Delta p) \\
& I_{\text {pro }}=Q_{\text {pro }} /(t \cdot \Delta p)
\end{aligned}
$$

where $I_{\text {in }}$ is injectivity index, $\mathrm{mL} /(\min \cdot \mathrm{MPa}) ; I_{p r o}$ is productivity index, $\mathrm{mL} /(\mathrm{min} \cdot \mathrm{MPa})$; $\Delta p$ is injection pressure difference, $\mathrm{MPa} ; Q_{i n}$ is injection volume, $\mathrm{mL} ; Q_{p r o}$ is production volume, $\mathrm{mL}$; $t$ is time, min.

Figure 1 shows the relationship between displacement pressure and flooding efficiency of oil sample in the carbon dioxide flooding experiment. The minimum miscibility pressure of oil sample is about $30 \mathrm{MPa}$. However, carbon dioxide and crude oil may have somewhat miscibility when the displacement pressure is smaller than the minimum miscibility pressure. The injectivity index and the productivity index of oil sample under various carbon dioxide flooding pressures are shown in Figure 2 and Figure 3. Under low displacement pressure, the injectivity index indicates an increasing trend with the increase of displacement pressure. While the displacement pressure reached 28.52 $\mathrm{MPa}$ (reached the near minimum miscibility pressure interval), the injectivity index apparently declined, indicating that the organic solid phase precipitation, deposition, even blocking existed in the model (Figure 2). The analogous performance is found in the variation trend of productivity index in Figure 3. Thus, for the test sample, the change occurred in high displacement pressure during the carbon dioxide flooding process. According to the further analysis of the carbon dioxide flooding processes of several samples, lots of them present the change and partial samples exhibit the most severe blockage. It is noted that all the experiments with the behavior possess equal or higher displacement pressure than the near minimum miscibility mean pressure, while for the remaining samples without the change, those pressure values just below the mean value. Therefore, during the carbon dioxide flooding process, the reservoir blockage primarily appears as the displacement pressure is higher than the near minimum miscibility lower limit pressure. However, high pressure environment test result for several samples showing similar final flooding efficiency. Therefore, the blockage is likely to make little impact on carbon dioxide flooding efficiency, but plays an important role in the production capacity. Extortionate or low pressure is not conducive to carbon dioxide displacement. 


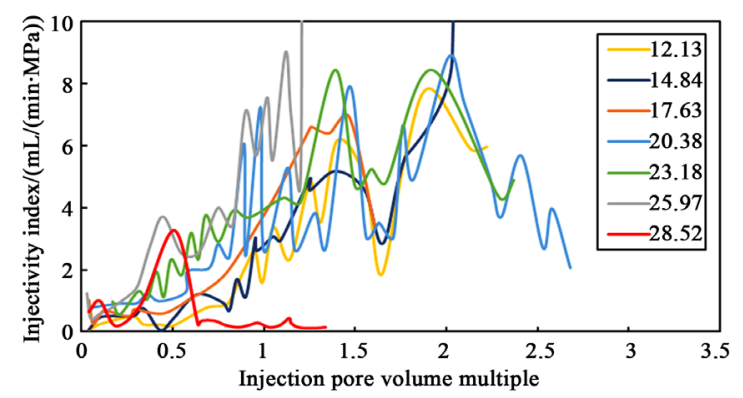

Figure 2. Relationship between injectivity index and PV.

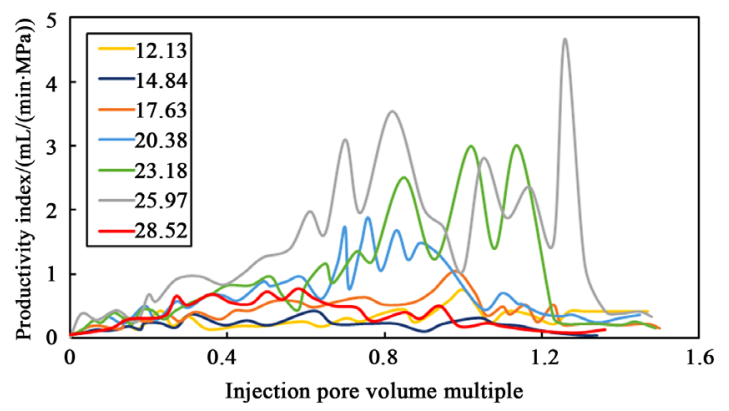

Figure 3. Relationship between productivity index and PV.

\section{Conclusion}

Slim tube experiment as the effective method was utilized in the research process to get the dynamic data. Near minimum miscibility pressure interval was determined. The results show that the closer to the miscibility pressure, the greater the organic solid phase precipitation and deposition probability. The displacement pressure reached the near minimum miscibility pressure interval, the injectivity index apparently declined, indicating that the organic solid phase precipitation, deposition, even blocking existed in the model system. The blockage is likely to make little impact on carbon dioxide flooding efficiency, but plays an important role in the production capacity. Controlling the pressure is an important link to prevent the occurrence of blockage in the flooding process. Extortionate or low pressure is not conducive to carbon dioxide displacement.

\section{Acknowledgements}

This work was financially supported by the Guangxi Natural Science Foundations (2016GXNSFBA380180, 2017GXNSFAA198105), the Guangxi Education Department Scientific Research Project (2017KY0792), the Beibu Gulf University Scientific Research Project (2016PY-GJ09), the Opening Project of Guangxi Colleges and Universities Key Laboratory of Beibu Gulf Oil and Natural Gas Resource Effective Utilization (2016KLOG01, 2017KLOG25).

\section{Conflicts of Interest}

The author declares no conflicts of interest regarding the publication of this paper. 


\section{References}

Björn, F. (1995). A Systematic Approach for the Prevention and Treatment of Formation Damage Caused by Asphaltene Deposition. International Journal of Rock Mechanics \& Mining Sciences \& Geomechanics Abstracts, 32, 260-282. https://doi.org/10.1016/0148-9062(95)90148-5

Dai, Z. (2018). Heterogeneity-Assisted Carbon Dioxide Storage in Marine Sediments. Applied Energy, 225, 876-883. https://doi.org/10.1016/j.apenergy.2018.05.038

Danesh, A., Krinis, D., Henderson, G. D., \& Peden, J. M. (1988). Asphaltene Deposition in Miscible Gas Flooding of Oil Reservoirs. Chemical Engineering Research \& Design, $66,339-344$.

Gale, J. (2004). Geological Storage of $\mathrm{CO}_{2}$ : What Do We Know, Where Are the Gaps and What More Needs to Be Done? Energy, 29, 1329-1338. https://doi.org/10.1016/j.energy.2004.03.068

Gershenzon, N. I. (2015). Influence of Small-Scale Fluvial Architecture on $\mathrm{CO}_{2}$ Trapping Processes in Deep Brine Reservoirs. Water Resources Research, 51, 8240-8256. https://doi.org/10.1002/2015wr017638

Haszeldine, R. S. (2009). Carbon Capture and Storage: How Green Can Black Be? Science, 325, 1647-1652. https://doi.org/10.1126/science.1172246

Mazzocchi, E., Nagel, R. G., Hunter, B. E., Peggs, J. K., \& Fong, D. K. (1998). Tertiary Application of a Hydrocarbon Miscible Flood: Rainbow Keg River "B" Pool. SPE Enhanced Oil Recovery Symposium.

Monger, T. G. (1985). The Impact of Oil Aromaticity on $\mathrm{CO}_{2}$ Flooding. Society of Petroleum Engineer Journal, 25, 865-874. https://doi.org/10.2118/12708-PA

Newberry, M. E., \& Barker, K. M. (2000). Organic Formation Damage Control and Remediation. SPE International Symposium on Formation Damage Control. https://doi.org/10.2118/58723-MS

Rathmell, J. J., Stalkup, F. J., \& Hassinger, R. C. (1971). A Laboratory Investigation of Miscible Displacement by Carbon Dioxide. Annual Fall Meeting of the Society of Petroleum Engineering. https://doi.org/10.2118/3483-MS

Shelton, J. L., \& Yarborough, L. (1977). Multiple Phase Behavior in Porous Media during $\mathrm{CO}_{2}$ or Rich-Gas Flooding. Journal of Petroleum Technology, 29, 1171-1178. https://doi.org/10.2118/5827-PA

Srivastava, R. K., Huang, S. S., \& Dong, M. Z. (1999). Asphaltene Deposition during $\mathrm{CO}_{2}$ Flooding: A Laboratory Assessment. SPE Production \& Facilities, 14, 235-245. https://doi.org/10.2118/59092-PA

Stalkup, F. I. (1983) Miscible Displacement. Society of Petroleum Engineers Richardson Meeting.

Tuttle, R. N. (1983). High-Pour-Point and Asphaltic Crude Oils and Condensates. Journal of Petroleum Technology, 35, 1192-1196. https://doi.org/10.2118/10004-PA

Zendehboudi, S., Ahmadi, M. A., Bahadori, A., Shafiei, A., \& Babadagli, T. (2013). A Developed Smart Technique to Predict Minimum Miscible Pressure: EOR Implications. The Canadian Journal of Chemical Engineering, 91, 1325-1337. https://doi.org/10.1002/cjce.21802

Zhang, N., Wei, M., \& Bai, B. (2018). Statistical and Analytical Review of Worldwide $\mathrm{CO}_{2}$, Immiscible Field Applications. Fuel, 220, 89-100.

https://doi.org/10.1016/j.fuel.2018.01.140 